муниципалитета МБУ ФОК «Олимп», ДЮСШ, Дом де детского творчества, Центр ремесел «Рассвет», районный дворец культуры, СМИ газета «Приволжская правда», Краеведческий музей г. Лысково, телекомпания Лысковское ТВ и др.

$$
* * *
$$

1. Игнатьева Г.А., Тулупова О.В. Проектно-ресурсное управление инновациями в образовании: антропологическая проекция // Современные исследования социальных проблем (электронный научный журнал). - 2015. № 5. С.490 - 509.

2. Игнатьева Г.А., Тулупова О.В., Крайникова М.Н. Стажировочная площадка как проектный полигон инновационного образования //«Педагогика и психология образования. «Вестник МПГУ им. М.А. Шолохова. Серия. Педагогика. Психология». - 2016. - № 2 - с. 56- 65

3. Игнатьева Г.А., Слободчиков В.И. Антропологическая перспектива развития человеческого потенциала образовательных систем. // Вопросы дополнительного профессионального образования, 2016. № 1 (5) с. 1 -18.

4. Методология (целевая модель) наставничества обучающихся для организаций, осуществляющих образовательную деятельность по общеобразовательным, дополнительным общеобразовательным и программам среднего профессионального образования, в том числе с применением лучших практик обмена опытом между обучающимися [Электронный ресурс] - Режим доступа: http://kobr.spb.ru/media/content/docs/5701/\%D0\%A6\%D0\%B5\%D0\%BB\%D0\%B5\%D0\%B2\%D0\%B0 \%D1\%8F_\%D0\%BC\%D0\%BE\%D0\%B4\%D0\%B5\%D0\%BB\%D1\%8C._5.12.2019_\%D0\%B4\%D0\%B B\%D1\%8F_\%D1\%80\%D0\%B0\%D1\%81\%D1\%81\%D1\%8B\%D0\%BB\%D0\%BA\%D0\%B8.pdf. Дата обращения 23.07.2021 г.

5. Программа по развитию личностного потенциала Благотворительного фонда Сбербанка РФ «Вклад в будущее». Электронная версия: https://vbudushee.ru/education/soderzhanieobrazovaniya/programma-po-razvitiyu-lichnostnogo-potentsiala/ (Дата обращения 23.07.2021).

6. Сафонова О.А. Компетентностный подход как методологический ориентир модернизации высшего профессионального образования. / Компетентностно-ориентированное обучение в вузе: теория и практика: монография / Мининский университет. Нижний Новгород, 2014. - 354 с. (c. 32 $-38)$

7. Универсальные компетентности и новая грамотность: от лозунгов к реальности / под ред. М.С. Добряковой, И.Д. Фрумина; при участии К.А. Баранникова, Н. Зиила, Дж. Мосс, И.М. Реморенко, Я. Хаутамяки; Нац. исслед. ун-т «Высшая школа экономики». - М.: Изд. дом Высшей школы экономики, 2020. - $472 \mathrm{c}$.

8. Ясвин В.А. Школьная среда как предмет измерения: экспертиза, проектирование, управление / В.А. Ясвин. - М.: Народное образование, 2019. - 448 с.

\title{
Савончик Г.С. \\ Особенности преподавания биологии студентам лечебного факультета в условиях дистанционного обучения в связи с особыми обстоятельствами
}

Медицинский институт ОГУ им. И.С. Тургенева (Россия, Орёл)

doi: $10.18411 / \mathrm{j}-08-2021-53$

\section{Аннотация}

В статье рассматриваются особенности обучения биологии на лечебном факультете в связи с переходом учебного процесса в дистанционный формат. Особое внимание уделяется организации самостоятельной работы студентов в этот период. Приводится пример задания для внеаудиторного выполнения практического занятия, формы и сроки его выполнения и итогового оценивания результатов работы.

Ключевые слова: дистанционное обучение, самостоятельная работа студентов, формат обучения, организация образовательного процесса.

\section{Abstract}

The article discusses the features of teaching biology at the faculty of Medicine in connection with the transition of the educational process to a distance format. Special attention is paid to the organization of independent work of students during this period. An 
example of a task for the extracurricular fulfillment of a practical lesson, the forms and terms of its performing and the final evaluation of the results of the work are given.

Keywords: distance learning, independent work of students, training format, organization of the educational process.

В ходе реализации современных образовательных программ могут возникать особые обстоятельства, которые предполагают временный переход учебного процесса в дистанционный формат. Такими обстоятельствами стали ограничения, связанные с распространением вируса COVID-19. В этом случае дистанционное обучение полностью заменяет традиционную очную форму. Очевидно, что для организации эффективного образовательного процесса необходимо создать целый комплекс условий, необходимый для его осуществления. Сохраняя основные дидактические принципы, дистанционное обучение имеет специфические черты, связанные с его организацией [2]. Его особенностью является, в первую очередь то, что несколько меняется роль преподавателя, преобладает самоконтроль над контролем с его стороны, используются специализированные дистанционные технологии и средства обучения, осуществляется активизация внеаудиторной самостоятельной работы студентов[1]. Она должна носить проблемный и творческий характер, так как призвана формировать и развивать навыки, которые будут в дальнейшем необходимы для выполнения различных учебных заданий, научных исследований, написания рефератов. Задания для самостоятельной работы должны соответствовать целям различного уровня, отражать содержание всех разделов (модулей) дисциплины, Также нельзя забывать, что организация самостоятельной (индивидуальной или групповой) работы обучающихся в любой форме должна быть направлена на формирование соответствующих компетенций [3].

В связи с объявленной пандемией, все студенты и преподаватели медицинского института Орловского государственного университета им. И.С. Тургенева были переведены на дистанционное обучение, в формате которого проводились как лекции, так и практические занятия по биологии на первом курсе. В основном оно осуществлялось через личные кабинеты на сайте университета и на платформе Zoom.

Для повышения эффективности самостоятельной работы при дистанционном обучении, студентам предоставлялись, каждой группе индивидуально, все необходимые учебные материалы в удобном формате. Они прикреплялись в разделе «методические материалы» личного кабинета. Такая организация обеспечила высокоэффективную обратную связь между студентами и преподавателем.

Сложность дистанционного обучения на первом курсе заключается с нашей точки зрения в том, что значительная часть вчерашних школьников не может самостоятельно организовать эффективную самостоятельную работу, а также нести ответственность за ее результаты, поэтому необходим постоянный контроль над этим процессом со стороны преподавателя.

Задания, которые мы предлагали для внеаудиторной работы носят исследовательский, информационный, творческий характер, позволяют формировать и развивать навыки самостоятельной работы, раскрыть внутренний потенциал каждого студента, сформировать у него необходимые личностные качества:

1) поиск литературы по соответствующей тематике;

2) подготовка к практическим занятиям по предложенным вопросам для обсуждения;

3) написание конспектов;

4) изучение дополнительных вопросов учебной программы по теме занятия, которые не вошли в раздел обсуждаемых;

5) анализ и решение генетических задач;

6) решение ситуационных задач; 
7) выполнение заданий исследовательского и творческого характера и другие.

Для формирования необходимых общепрофессиональных компетенций мы предлагаем задания следующего характера:

- информационные: поиск, обработка и представление информации из разных литературных источников; обобщение, систематизация и классификация информации; работа с общебиологическими понятиями;

- проблемные: анализ фотокариограмм человека, решение ситуационных задач по паразитологии, решение генетических задач;

- экспериментальные: наблюдения в природе; проведение экспериментов и получение новых данных для анализа и применения знаний на практике.

Для примера рассмотрим выполнение внеаудиторной самостоятельной работы по теме занятия «Генетика человека. Введение в медицинскую генетику». Основные цели занятия:

1. Понять особенности человека, как объекта генетического анализа.

2. Научиться применять основные методы генетики человека.

3. Изучить роль наследственности и среды в формировании признаков.

4. Изучить генетические механизмы возникновения наследственной патологии.

5. Изучить основные задачи медико-генетического консультирования, направленные на предотвращение развития наследственной патологии.

Перед студентами стояли следующие задачи:

1) определить тип наследования признаков в предложенных родословных;

2) применить закон Харди-Вайнберга для определения частот генов и генотипов в популяции;

3) провести анализ фотокариограммы человека;

4) решить ситуационные задачи.

На одно практическое занятие по учебному плану отводится четыре академических часа. Первые два часа проходят в виде онлайн конференции на платформе Zoom, во время которой разбираются теоретические вопросы, предложенные для обсуждения заранее. Затем преподаватель проводит поэтапную постановку конкретных задач, распределяет задания между студентами. Они могут быть индивидуальными для каждого, для 2-3 человек, или для всей группы. Также преподаватель устанавливает форму отчета студентов о выполненной работе и сроки ее выполнения. В нашем случае, студенты выполняли работу в тетради для практических занятий, соблюдая требования, указанные в методических материалах, фотографировали и высылали преподавателю в определенный им срок. Срок выполнения не должен превышать длительности практического занятия по расписанию. В нашем случае это ещё два академических часа после окончания конференции. Итоговая оценка выставлялась преподавателем в личном кабинете в разделе «текущая успеваемость». При ее выставлении учитывалось участие студента в обсуждении предложенных теоретических вопросов, верное решение поставленных задач, а также соблюдение формы и сроков выполнения практического задания.

В условиях пандемии, в дистанционном формате проводились не только практические занятия, но и лекции, консультации, экзамены, а также ежегодная студенческая научная конференция, и эта форма обучения была незаменима. Но необходимо отметить, что в процессе ее применения мы столкнулись с рядом проблем:

1) технические трудности в обеспечении процесса обучения;

2) высокая степень зависимости от корректной работы необходимого оборудования и от возможности выхода в Интернет; 
3) значительное повышение нагрузки на преподавателя: повышаются временные затраты на разработку дистанционных курсов и отдельных заданий, создание презентаций, консультирование и проведение итогового контроля;

4) необходимость приобретения специфических знаний и повышения компьютерной грамотности;

5) затруднительное проведение занятий с иностранными студентами из-за сложностей в преодолении языкового барьера;

6) невозможность обучения некоторым видам практической деятельности (например, работе с микроскопом).

Несмотря на это, такой формат обучения был самым актуальным. Он позволил нам решать образовательные задачи в тех особых обстоятельствах, которые сложились в непростой период распространения вирусной инфекции.

$$
* * *
$$

1. Ганичева И.А., Морозов А.В. Организация самостоятельной работы студентов в условиях дистанционного обучения.//Образование и право. 2020 г. - №12. - С.238-242.

2. Милованова Г.В. Самостоятельная работа студентов в условиях дистанционного образования.//Гуманитарий: актуальные проблемы гуманитарной науки и образования. 2014 г. №3. - С.72-76.

3. Акулова Т.Н. Организация самостоятельной работы студентов Педагогического факультета в структуре компетентностного подхода /Т.Н.Акулова, И.Г.Андреева //Компетентностный подход как концептуальная основа современного образования: Сборник научных статей / Под ред. С.Л. Коротковой, С.В. Фроловой. - Саратов: ИЦ «Наука», 2010. - С. 31-33.

\section{Сивкина Н.Ю., ${ }^{1,2}$ \\ Интерактивный формат групповой работы студентов \\ ${ }^{1}$ Нижегородский государственный университет им. Н.И. Лобачевского ${ }^{2}$ Научно-образовательный центтр Нижегородского государственного лингвистического университета им. Н.А. Добролюбова, «Славяно-греко-латинский кабинет»} (Россия, Нижний Новгород)

doi: $10.18411 / \mathrm{j}-08-2021-54$

\section{Аннотация}

В данной работе автор исследует отношение студентов к разным формам проведения семинарских занятий. По мнению автора, успешный результат современного процесса обучения кроется в групповой работе студентов, позволяющей решать многофункциональные задачи, в разнообразии форм проведения занятий, в динамике самого занятия. Интерактивные формы обучения отвечают психологическим особенностям и ценностям современного поколения студентов.

Ключевые слова: история, интерактивная форма обучения, ролевая игра, проектная деятельность, групповая работа.

\section{Abstract}

In this paper, the author examines the attitude of students to different forms of conducting seminars. According to the author, the successful result of the modern learning process lies in the group work of students, which allows them to solve multifunctional tasks, in the variety of forms of classes, in the dynamics of the class itself. Interactive forms of education meet the psychological characteristics and values of the modern generation of students.

Keywords: history, interactive form of learning, role-playing game, project activity, group work. 